\title{
Molecular detection of porcine circovirus type 3 in Shanxi Province, China
}

\author{
Weidong Yue, Yihui Liu, Xinrong Zhang, Haili Ma* and Junping He*
}

\begin{abstract}
Porcine circovirus type 3 (PCV3), which was first detected in the United States of America in 2015, is a potential threat to the swine industry. However, the prevalence of PCV3 in Shanxi Province, China, is unclear. In this research, the prevalence and genetic diversity of PCV3 were investigated in above area. Lung tissue samples $(n=491)$ from 19 pig slaughterhouses across 11 cities throughout Shanxi Province were analyzed for PCV3 infection by PCR in 2019. The results showed that PCV3 positive rates in slaughterhouses and individuals were 100\% (19/19) and 86.76\% (426/491), respectively. PCV2 and PCV3 double-positive rates in slaughterhouses and individuals were 100\% (19/19) and 59.27\% (291/491), respectively. PCR positive samples were further sequenced and 8 PCV3 isolates were identified. The nucleotide homology of these isolates with other PCV3 isolates in NCBI database was 97.45-99.90\%. A phylogenetic analysis, based on the complete genomic sequence and ORF2, divided these PCV3 strains into 2 major groups. Based on $A^{24} N$ and $R^{27} / K$ amino acid mutations of capsid protein, the 8 identified PCV3 strains were separated to 2 clades. This was the first detailed investigation into the epidemiology of PCV3 in Shanxi Province. Our findings enabled us to assess the possibility of widespread transmission from this region. Thus, current findings establish a basis for further studies of genetic variations in PCV3 strains circulating in China.
\end{abstract}

Keywords: Circovirus, Prevalence, Porcine circovirus type 3 (PCV3), Phylogenetic analysis

\section{Background}

Circoviruses are small nonenveloped viruses with a circular icosahedral structure; they exhibit unique characteristics among animal viruses based on their circular, single-stranded DNA genome composed of 2000 nucleotides (nt) (Todd et al. 2001; Rosario et al. 2017). Circoviruses belong to Circoviridae family and cause infection in different animals, including pigs and dogs (Segales et al. 2012; Bexton et al. 2015; Tarján et al. 2014). Only 2 circoviruses have been previously reported in pigs, namely, the closely related porcine circovirus type 1 (PCV1) and porcine circovirus type 2 (PCV2) (Hamel et al. 1998; Allan et al. 2012). PCV1 is considered nonpathogenic to swine (Chen et al. 2014), whereas PCV2 infection can cause

\footnotetext{
*Correspondence: mahaili1718@126.com; junpinghe@aliyun.com College of Veterinary Medicine, Shanxi Agricultural University, Taigu, Shanxi 030801, People's Republic of China
}

porcine dermatitis and nephropathy syndrome (PDNS), reproductive failure, and respiratory and enteric manifestations (Gillespie et al. 2009; Opriessnig and Langohr 2013; Tomás et al. 2010).

In 2015, a new circovirus species was identified in pigs affected by PDNS, respiratory disease, and multisystemic inflammation. It was first reported in the United States and was named porcine circovirus 3 (PCV3) (Phan et al. 2016; Palinski et al. 2017; Klaumann et al. 2018). PCV3 contains a circular genome of $2000 \mathrm{nt}$, and 3 open reading frames (ORFs) have been identified. ORF1 encodes the replication-associated protein (Rep); ORF2 encodes the capsid (Cap) protein; and ORF3 encodes an unknown function protein (Wen et al. 2018; Fu et al. 2018). Rep drives viral replication. Cap protein, the major structural protein, is composed of 214 amino acids (aa) and determines antigenic characteristics of circoviruses (Nawagitgul et al. 2000).

C The Author(s). 2021 Open Access This article is licensed under a Creative Commons Attribution 4.0 International License, which permits use, sharing, adaptation, distribution and reproduction in any medium or format, as long as you give appropriate credit to the original author(s) and the source, provide a link to the Creative Commons licence, and indicate if changes were made. The images or other third party material in this article are included in the article's Creative Commons licence, unless indicated otherwise in a credit line to the material. If material is not included in the article's Creative Commons licence and your intended use is not permitted by statutory regulation or exceeds the permitted use, you will need to obtain permission directly from the copyright holder. To view a copy of this licence, visit http://creativecommons.org/licenses/by/4.0/. The Creative Commons Public Domain Dedication waiver (http://creativecommons.org/publicdomain/zero/1.0/) applies to the data made available in this article, unless otherwise stated in a credit line to the data. 
On a global scale, PCV3 has been reported in several countries, including China, USA, Italy, Brazil, Korea, Spain and Russia (Ku et al. 2017; Phan et al. 2016; Stadejek et al. 2017; Faccini et al. 2017; Kwon et al. 2017; Ye et al. 2018; Yuzhakov et al. 2018; Geng et al. 2019). The nationwide prevalence of PCV3 in the USA was reported to be $44.2 \%$ (Palinski et al. 2017). In Europe, the highest positive rates were $75 \%$ and $65 \%$ in Germany and Poland, respectively (Fu et al. 2018; Stadejek et al. 2017), whereas a prevalence of $44.2 \%$ was reported in Korea (Kwon et al. 2017). PCV3 has also spread extensively among swine in Thailand, where a positive rate of $36.7 \%$ was previously reported (Sukmak et al. 2019).

The first case of PCV3 in China was documented in Guangdong Province in March 2017 (Shen et al. 2018). Since then, PCV3 cases have been widely identified in major hog producing provinces, such as Jiangxi, Fujian, Shandong and Liaoning ( $\mathrm{Fu}$ et al. 2018; Zheng et al. 2017; Qi et al. 2019; Liu et al. 2019). In China, high positive rates have been reported in Anhui (20.0\%), Jiangsu (26.7\%), Zhejiang (23.3\%) and Hunan provinces (45.9\%), and Chongqing City (16.7\%) (Liu et al. 2019; Zou et al. 2018).

China plays a major role in global pork production and has the world's highest pork consumption rate (Beltran-Alcrudo et al. 2019). Shanxi is a major agricultural province with several commercial pig farms. Slaughterhouses near farms can indicate a broader infection rate in the area where pigs were slaughtered there. Therefore, in this study, we collected samples from pig slaughterhouses across Shanxi Province, China, and conducted an extensive epidemiological investigation and phylogenetic analyses of PCV3 strains. These findings establish a basis for further investigation into PCV3 evolution and spread in China.

\section{Results}

In order to analyze the infection, diffusion and distribution of PCV3 in Shanxi Province, this study collected 491 samples from 19 slaughterhouses in 11 cities. Positive rates were detected and analyzed by PCR. PCV3 positive rates in slaughterhouses and individuals were 100\% (19/19) and 86.76\% (426/491), respectively. PCV2 and PCV3 double-positive rates in slaughterhouses and individuals were $100 \%(19 / 19)$ and $59.27 \%$ (291/491), respectively (Table 1). The presence of PCV3 in all 19 slaughterhouses was indicative of its widespread dissemination in Shanxi Province (Fig. 1). These results revealed that PCV3 infection is common in this area.

To analyze genetic relationship of PCV3 strains collected in Shanxi Province, 8 PCV3 positive samples were randomly selected for further investigation. Complete sequences of PCV3 genome were amplified and sequenced. Their genomes were 2000-2003 nt in length. The 8 isolates were identified as PCV3 strains for the complete genomic sequences exhibited 97.45-99.90\% identity with other PCV3 isolates available in NCBI database while $95.97-100 \%$ identity of ORF2. Furthermore, these 8 Shanxi PCV3 strains shared 98.65-99.45\% nt identity among themselves.

Neighbor joining phylogenetic tree analysis based on the complete genome revealed a close evolutionary relationship between PCV3/CN/SX08/2019 and PCV3-USAMO2015 (KX778720) isolates and PCV3/CN/SX04/2019 and PCV3/CH/GX/2242/2018 (MH823219) isolates. $\mathrm{PCV} 3 / \mathrm{CN} / \mathrm{SX} 08 / 2019$ isolate from China and the first isolate (PCV3-USA-MO2015) from USA were clustered together. PCV3/CN/SX04/2019 was clustered with PCV3/CH/GX/2242/2018 (MH823219) found in Guangxi. The 35 full-length genomic sequences obtained from GenBank and the 8 Shanxi PCV3 strains were

Table 1 Prevalence of PCV-3 in the Shanxi Province

\begin{tabular}{lcccc}
\hline Region & \multicolumn{2}{c}{$\begin{array}{c}\text { PCV3 positive rate } \\
\text { (Number) \% }\end{array}$} & \multicolumn{2}{c}{$\begin{array}{c}\text { PCV3 and PCV2 co-positive rate } \\
\text { (Number) \% }\end{array}$} \\
\cline { 2 - 4 } & Slaughterhouse & Individual & Slaughterhouse & $(1 / 1) 100$ \\
Datong & $(1 / 1) 100$ & $(27 / 27) 100$ & $(2 / 2) 100$ & $(30 / 52) 57.69$ \\
Shuozhou & $(2 / 2) 100$ & $(41 / 52) 78.85$ & $(2 / 2) 100$ & $(36 / 52) 69.23$ \\
Xinzhou & $(2 / 2) 100$ & $(46 / 52) 15.38$ & $(1 / 1) 100$ & $(6 / 22) 27.27$ \\
Taiyuan & $(1 / 1) 100$ & $(14 / 22) 63.64$ & $(1 / 1) 100$ & $(4 / 28) 14.29$ \\
Yangquan & $(1 / 1) 100$ & $(20 / 28) 71.43$ & $(2 / 2) 100$ & $(32 / 54) 59.26$ \\
Lvliang & $(2 / 2) 100$ & $(50 / 54) 92.59$ & $(2 / 2) 100$ & $(14 / 49) 28.57$ \\
Jinzhong & $(2 / 2) 100$ & $(43 / 49) 87.76$ & $(2 / 2) 100$ & $(27 / 50) 54.00$ \\
Linfen & $(2 / 2) 100$ & $(45 / 50) 90.00$ & $(2 / 2) 100$ & $(40 / 54) 70.07$ \\
Changzhi & $(2 / 2) 100$ & $(48 / 54) 96.30$ & $(2 / 2) 100$ & $(45 / 51) 88.24$ \\
Yuncheng & $(2 / 2) 100$ & $(44 / 51) 86.27$ & $(2 / 2) 100$ & $(42 / 52) 80.77$ \\
Jincheng & $(2 / 2) 100$ & $(44 / 52) 84.62$ & $(19 / 19) 100$ & $(291 / 491) 59.27$ \\
Total & $(19 / 19) 100$ & $(426 / 491) 86.76$ & & \\
\hline
\end{tabular}




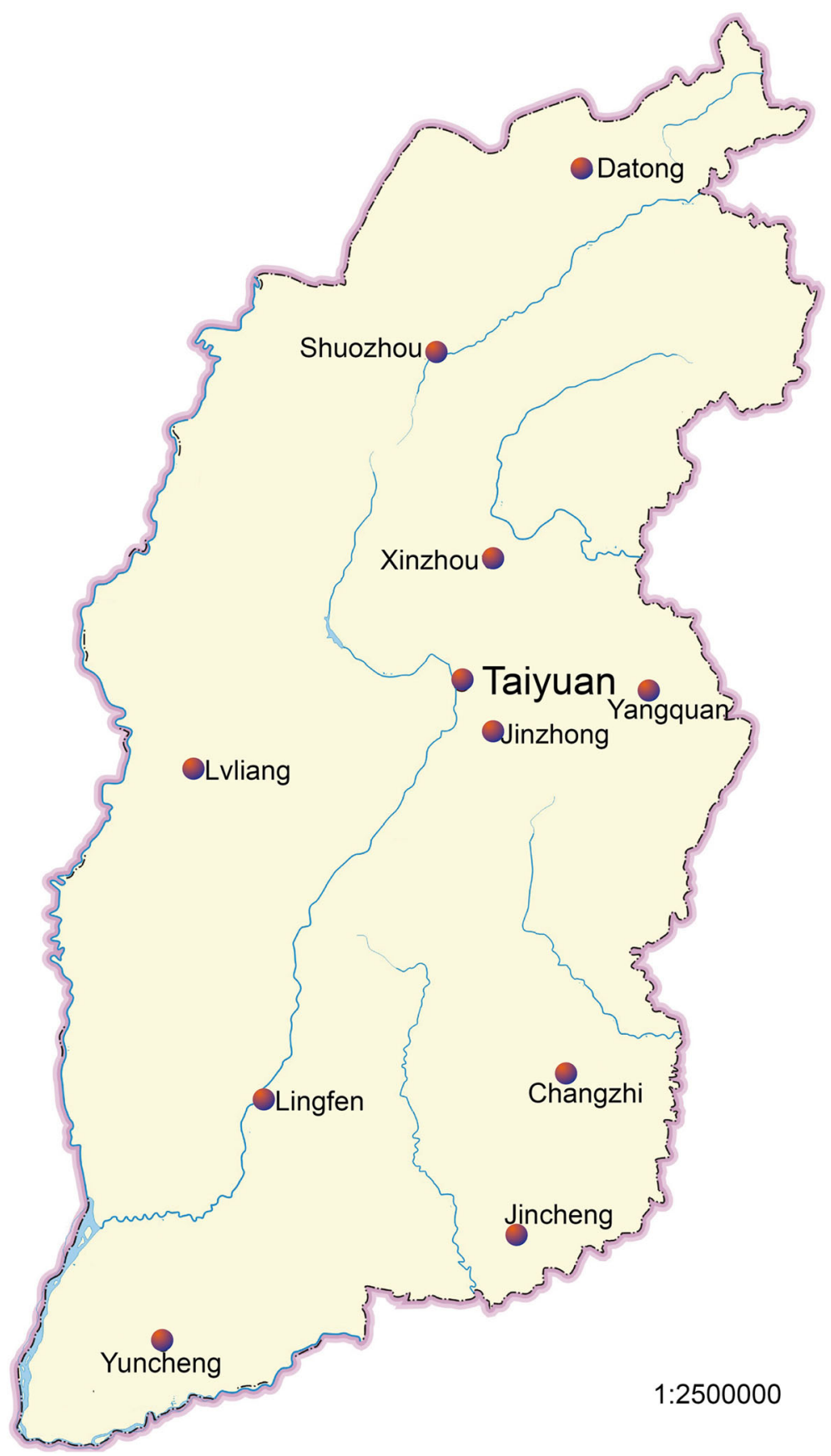

Fig. 1 Geographical distribution of PCV3 in Shanxi Province, China (censor code of this map: GS (2019) 3333). Red dots represent the regions with PCV3 positive samples

divided into 2 main groups (Fig. 2), indicating relatively independent genetic diversity of PCV3 strains in Shanxi Province. ORF2 phylogenetic tree discovery diagram showed similar results. Thirty five strains from GenBank and 8 PCV3 strains from Shanxi were divided into 2 groups, and the 8 PCV3 strains clustered into 2 clades (Fig. 3). Interestingly, a close evolutionary relationship was found between PCV3/CN/SX04/2019 and the identified strain PCV3/Guangxi-LZ/03, which differs from genome wide analysis.

Cap proteins of the 8 PCV3 strains were analyzed for amino acid mutations, including $\mathrm{A}^{24} / \mathrm{V}$ and $\mathrm{R}^{27} / \mathrm{K}$. PCV3 strains were divided into 3 clades based on $\mathrm{A}^{24} / \mathrm{V}$ and $\mathrm{R}^{27} / \mathrm{K}$ mutations. Amino acid mutations in $\mathrm{PCV} 3 / \mathrm{CN} /$ SX01/2019 were at A24 and K27, and based on this finding, the strain was identified as PCV3b. All of the 


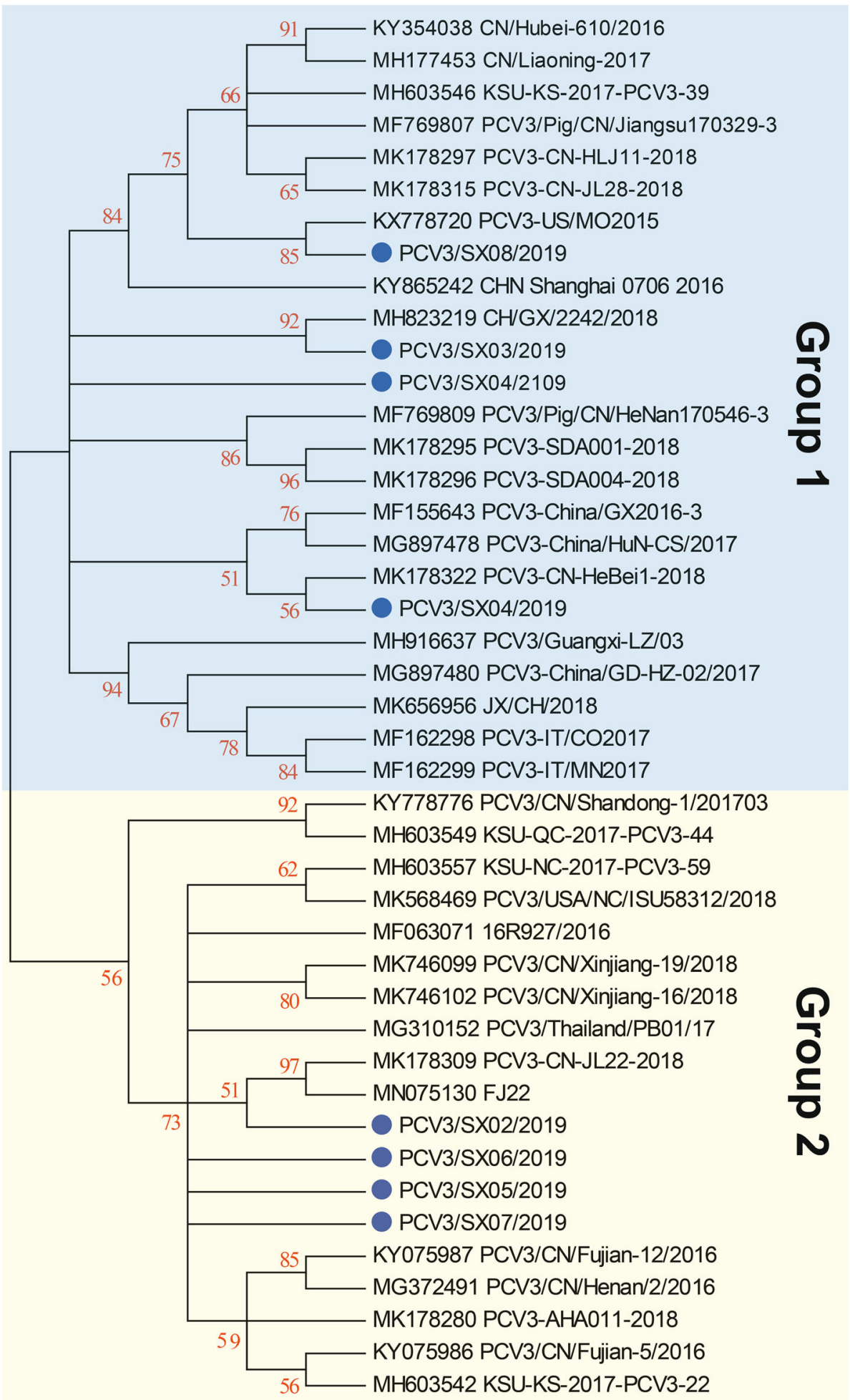

Fig. 2 Phylogenetic tree of the complete sequences of porcine circovirus type 3 (PCV3). Blue dots indicate PCV3 strains investigated in this study

remaining7 strains all had mutations at A24 and K27 sites and were therefore identified as PCV3a (Fig. 4). Other mutations were also observed in PCV3/CN/SX01/
$2019\left(\mathrm{~F}^{104} / \mathrm{Y}\right), \mathrm{PCV} 3 / \mathrm{CN} / \mathrm{SX} 04 / 2019\left(\mathrm{~N}^{56} / \mathrm{D}, \mathrm{Q}^{98} / \mathrm{R}\right)$ and $\mathrm{PCV} 3 / \mathrm{CN} / \mathrm{SX} 03 / 2019\left(\mathrm{~F}^{104} / \mathrm{Y}\right)$. The remaining strains did not harbor any Cap mutations. Whether these 


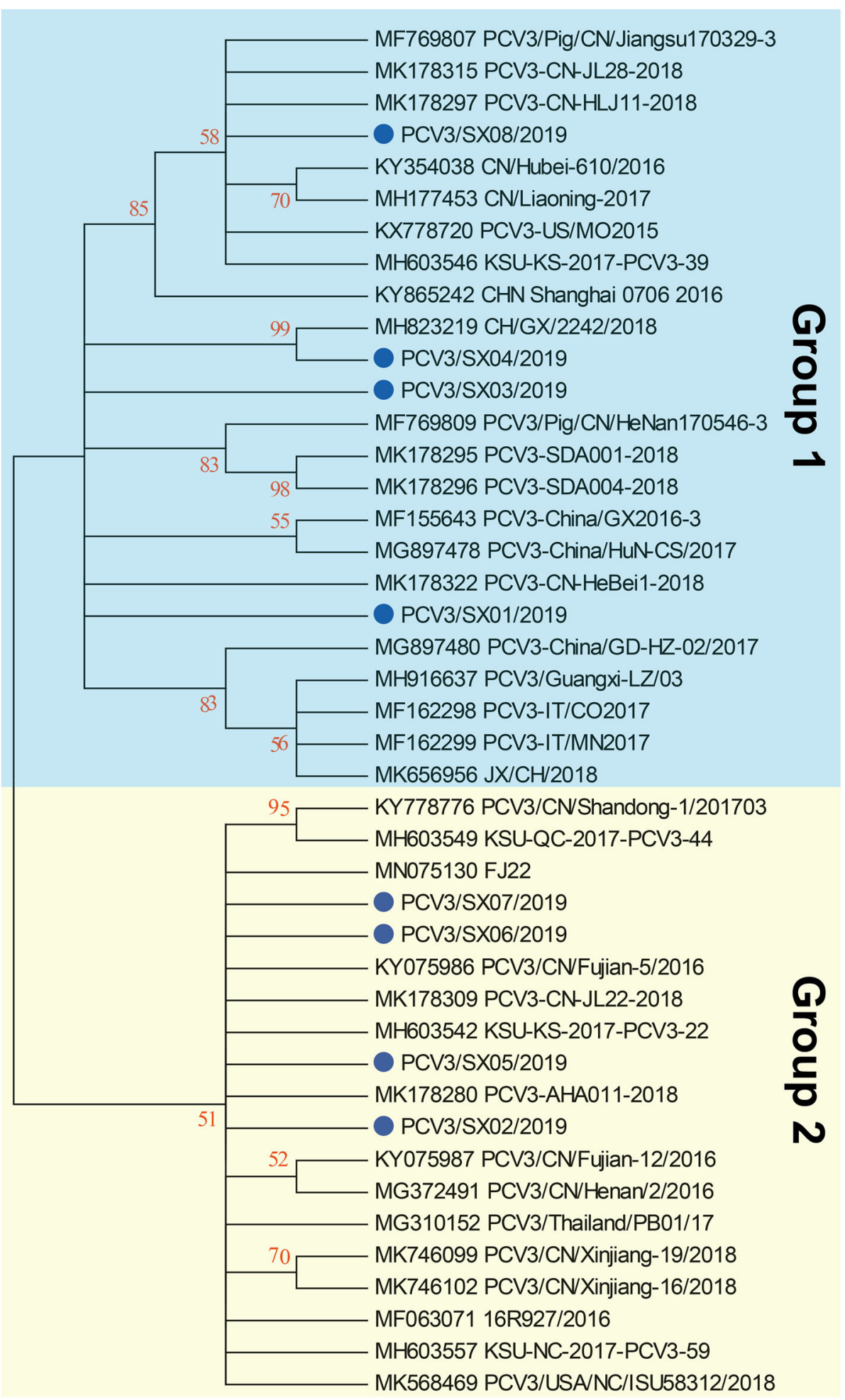

Fig. 3 Phylogenetic tree of ORF2 of porcine circovirus type 3 (PCV3). Blue dots indicate PCV3 strains investigated in this study 


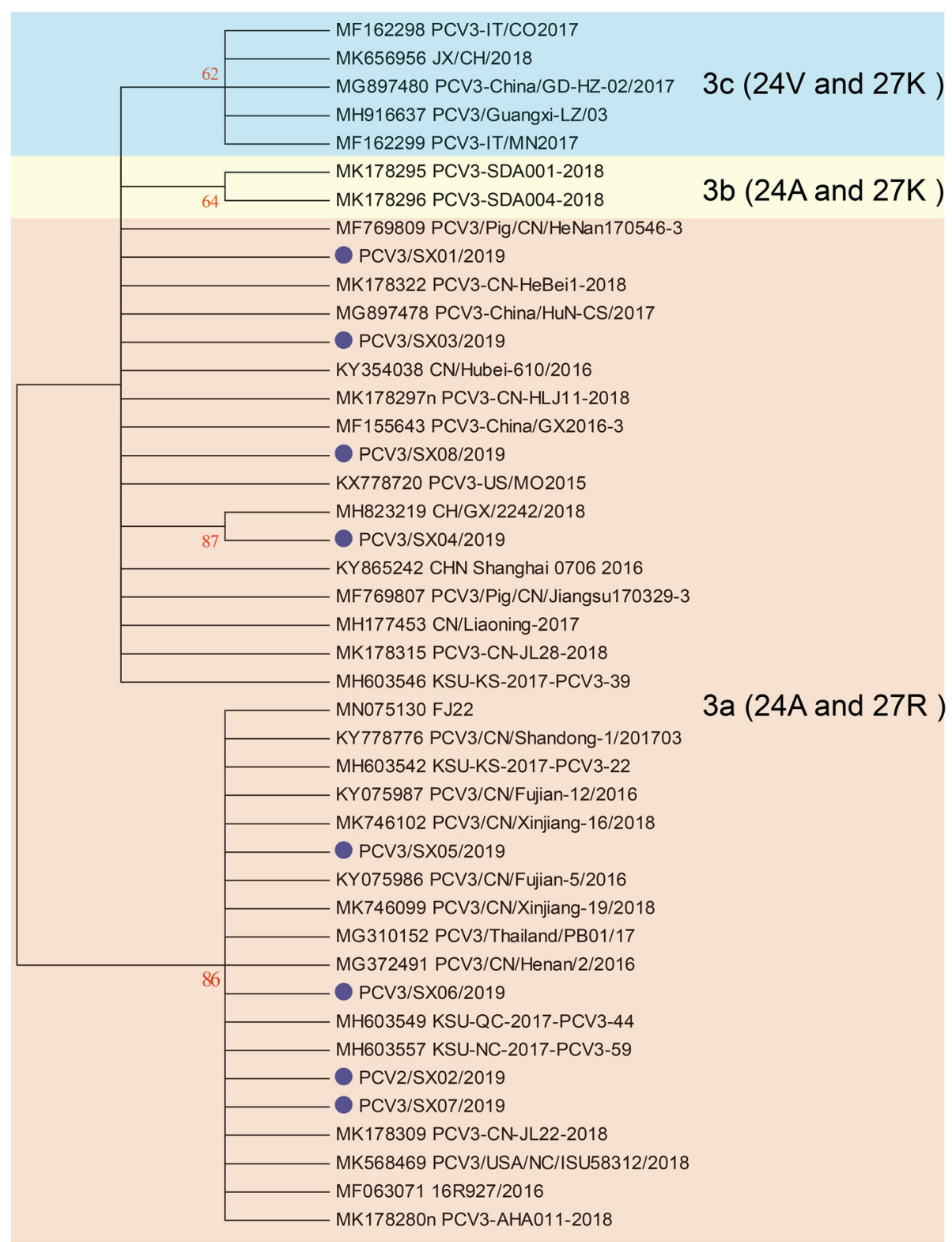

Fig. 4 Phylogenetic tree and amino acid alignment based on the Cap encoding gene of 35 porcine circovirus type 3 (PCV3) strains. PCV3 strains clustered into 3 subgroups, namely, 3a, 3b, and 3c. Blue dots indicate PCV3 strains investigated in this study

mutations affect Cap protein antigenicity remains to be addressed with further research.

\section{Discussion}

An intensive pig farming system may contribute to the rapid transmission of PCV3. Similarly, the global trade of pig breeding, porcine semen collection, and pork production also have a major impact on the global transmission of PCV3 (Liu et al. 2019). A rather wide PCV3 distribution was also confirmed in Europe ( $\mathrm{Fu}$ et al. 2018; Franzo et al. 2018). In a study conducted in Korea, PCV3 positive rates were $72.6 \%$ (53/73) and 44.2\% (159/
360) at farm and individual levels, respectively (Liu et al. 2019). In this study, PCV3 positive rate and PCV2 and PCV3 double-positive rate were $86.76 \%$ (426/491) and $59.27 \%$ (291/491), respectively, indicating that PCV3 has spread widely in Shanxi Province. Although PCV3 associated epidemics have been reported in Shanxi Province, no detailed epidemiological data or complete PCV3 sequences were previously reported.

Considering these findings, it is necessary to elucidate genetic data for PCV3 virus. Because isolation and culture of PCV3 are difficult, most recent studies have focused on the genetic characteristics of the virus. Thus, 
further sequencing of PCV3 positive samples was performed to identify 8 PCV3 isolates. Subsequently, phylogenetic analyses were performed based on PCV3 genomes.

Genome sequencing results revealed that PCV3 genomes composed of about 2000 nt; this observation was similar to the genomes reported for most strains isolated previously (Shen et al. 2018). As described earlier, PCV3 genome contains 3 ORFs, including the inversely arranged ORF1 and ORF2 encoding Rep and Cap proteins, respectively (Palinski et al. 2017; Ku et al. 2017). For phylogenetic analysis, the full-length genomes and ORF2 of PCV3 strains from different geographical locations were retrieved from NCBI nucleotide database and used as reference sequences.

Phylogenetic tree analysis showed that $\mathrm{PCV} 3 / \mathrm{CN} /$ SX08/2019 and PCV3/CN/SX04/2019 were closely related to the first reported PCV3 strain PCV3-USAMO2015 (KX778720) and to PCV3/CH/GX/2242/2018 (MH823219) from Guangxi, China, respectively. The 8 Shanxi PCV3 strains were found to be evenly distributed in 2 groups (Figs. 2 and 3). Moreover, no regional linkage was found among domestic and foreign PCV3 gene sequences selected from GenBank. The 8 detected PCV3 distributed in different regions of phylogenetic tree, still showed no regional characteristics. These results indicated that the 8 PCV3 strains from Shanxi Province were not geographically related with genetic diversity.

PCV3 Cap protein encoded by ORF2 is the main immunogenic protein of the virus (Qi et al. 2019). Therefore, ORF2 was subjected to phylogenetic analysis. The capsid-encoding genes of the 8 Shanxi PCV3 isolates exhibited $93.93-100 \%$ aa identity with those of other PCV3 isolates available in NCBI. Furthermore, the Shanxi strains shared a 98.13-100\% amino acid similarity. Previous studies suggested that $\mathrm{A}^{24} / \mathrm{V}$ and $\mathrm{R}^{27} / \mathrm{K}$ mutations in Cap protein and molecular marker data could be used to define PCV3 clades (Palinski et al. 2017; Qi et al. 2019). The 8 identified PCV3 strains belonged to 2 clades based on aa mutations in capsid protein $A^{24} / V$ and $R^{27} / K$. Interestingly, other mutations were also observed in PCV3/CN/SX01/2019 ( $\left.\mathrm{F}^{104} / \mathrm{Y}\right), \quad \mathrm{PCV} 3 / \mathrm{CN} / \mathrm{SX} 04 / 2019$ $\left(\mathrm{N}^{56} / \mathrm{D}, \mathrm{Q}^{98} / \mathrm{R}\right)$ and $\mathrm{PCV} 3 / \mathrm{CN} / \mathrm{SX} 03 / 2019\left(\mathrm{~F}^{104} / \mathrm{Y}\right)$. The remaining strains did not harbor any Cap mutations. Whether these mutations affect Cap protein antigenicity remains to be clarified.

\section{Conclusions}

This study was the first detailed investigation into epidemiology of PCV3 in Shanxi Province, China. Because pathogenicity and antigenicity vary among clades, PCV3 strains require further studies. Our findings regarding
PCV3 phylogeny provide useful information for further studies in virus evolution and establish a basis for further analysis of genetic variation of PCV3 strains circulating in China.

\section{Methods}

\section{Sample information and DNA isolation}

Lung tissue samples $(n=491)$ were collected from 19 pig slaughterhouses, accounting for approximately $14 \%$ of all slaughterhouses (approximately 140 slaughterhouses), in 11 cities (Datong, Xizhou, Shuozhou, Taiyuan, Yangquan, Lvliang, Jinzhong, Linfen, Changzhi, Yuncheng and Jinchen) throughout Shanxi Province, China, in 2019. The daily slaughter capacity of each slaughterhouse was 1000-2000 animals (Fig. 1 ). Porcine lung tissues were randomly collected from the slaughterhouse production line, washed with sterile saline and transported back to the laboratory within $12 \mathrm{~h}$ in an ice bath. Lung tissue was washed with sterile saline, homogenized, diluted 10 -fold with phosphate buffered saline, and stored at $-80^{\circ} \mathrm{C}$ until DNA extraction was performed. After freeze-thawing 3 times to release the virus, all samples were centrifuged at $10,000 \mathrm{~g}$ for $10 \mathrm{~min}$ at $4{ }^{\circ} \mathrm{C}$, and the supernatants were collected (Xu et al. 2018). DNA was extracted using a TIANamp Genomic DNA Kit (Tiangen, Beijing, China) according to the manufacturer's instructions.

\section{PCV3 determination and sequencing of the full-length genome}

PCR was performed using genomic DNA to amplify the complete viral genome of PCV3. Three primer pairs were used to amplify the complete genome of identified PCV3 strains, and one primer pair was used for PCV3 detection (Table 2).

For PCR-based PCV3 detection, mixture contained 1.5 $\mu \mathrm{L}$ extracted DNA, $1 \mu \mathrm{L}$ primers $(10 \mu \mathrm{M}), 10 \mu \mathrm{L}$ PCR Mix

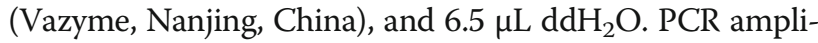
fication procedure was as follows: predenaturation at $94^{\circ} \mathrm{C}$ for $5 \mathrm{~min}$; 34 cycles of denaturation at $94^{\circ} \mathrm{C}$ for $30 \mathrm{~s}$, annealing at $55^{\circ} \mathrm{C}$ for $30 \mathrm{~s}$, and extension at $72^{\circ} \mathrm{C}$ for $30 \mathrm{~s}$; followed by a final extension step at $72^{\circ} \mathrm{C}$ for $7 \mathrm{~min}$.

For PCV3 full-length genomic PCR, mixture contained $1.5 \mu \mathrm{L}$ extracted DNA, $1 \mu \mathrm{L}$ primers $(10 \mu \mathrm{M}), 10 \mu \mathrm{L}$ PCR Mix (Vazyme), and $6.5 \mu \mathrm{L} \mathrm{ddH}_{2} \mathrm{O}$. Three overlapping segments spanning the entire genome were amplified. PCR amplification procedure was as follows: predenaturation at $95^{\circ} \mathrm{C}$ for $5 \mathrm{~min} ; 35$ cycles of denaturation at $94^{\circ} \mathrm{C}$ for $30 \mathrm{~s}$, annealing at $56^{\circ} \mathrm{C}$ for $30 \mathrm{~s}$, and extension at $72^{\circ} \mathrm{C}$ for $60 \mathrm{~s}$; and a final extension step at $72^{\circ} \mathrm{C}$ for $10 \mathrm{~min}$.

PCR products were analyzed using 2\% agarose gels in Tris-acetic-acid-EDTA buffer and stained with 
Table $\mathbf{2}$ List of primers used in this study

\begin{tabular}{|c|c|c|c|c|}
\hline Primer name & Nucleotide sequence & Product length (bp) & Purpose & References \\
\hline PCV3-1-F & 5'-TGCTACGAGTGTCCTGAAGAT-3' & 442 & Detection & Fu et al. 2018 \\
\hline PCV3-1-R & 5'-CTTCTCCGCAACTTCAGTCAG-3' & & & \\
\hline PCV2-F & 5'-TTAGG GTTAAGTGGGG GGTC-3' & 470 & Detection & Zhou et al. 2018 \\
\hline PCV2-R & 5'-CCGGATCCATGACGTACCCAAGGAGGCG-3' & & & \\
\hline PCV3-genome-1-F & 5'-ATTATGGATGCTCCTCATCGTG-3' & 553 & Genome sequencing & Wen et al. 2018 \\
\hline PCV3-genome-1-R & 5'-CATCTTCTCCGCAACTTCAGTC-3' & & & \\
\hline PCV3-genome-2-F & 5'-GACTGAAGTTGCGGAGAAGATG-3' & 789 & Genome sequencing & Wen et al. 2018 \\
\hline PCV3-genome-2-R & 5'-CGGCACGAAAGAAGTTTGGATT-3' & & & \\
\hline PCV3-genome-3-F & 5'-CCCACATGCGAGGGCGTTACC-3' & 895 & Genome sequencing & Wen et al. 2018 \\
\hline PCV3-genome-3-r & 5'-CGAGGCCGCTTCATCATCCACT-3' & & & \\
\hline
\end{tabular}

GelRed (Biosharp, Hefei, China), followed by visualization under ultraviolet illumination. Totally 8 PCV3 infected positive samples from different regions were randomly selected for full gene amplification. PCR products were analyzed with Sanger sequencing by Sangon (Shanghai, China) and were designated as PCV3/CN/SX01-SX08/2019.

\section{Phylogenetic analysis of PCV3 strains}

Complete genomes $(n=35)$ of PCV3 strains from different geographical locations were retrieved from NCBI database, including other regions of China and other countries worldwide. Multiple sequence alignments of PCV3 strains, including which identified in this study, were performed using the Clustal W method (DNASTAR Inc.). The phylogenetic relationships were assessed using neighbor-joining phylogenetic tree methods, the p-distance model with 1000 bootstrap replicates, and the remaining default parameters with MEGA software (MEGA 6.06) (Ku et al. 2017; Wen et al. 2018).

\section{Abbreviations}

PCV1: Porcine circovirus type 1; PCV2: Porcine circovirus type 1; PCV3: Porcine circovirus type 3; PCR: Polymerase chain reaction; nt: Nucleotides; PNDS: Porcine dermatitis and nephropathy syndrome; ORF: Open reading frame; Rep: Replication-associated protein; Cap: Capsid; aa: Amino acids

\section{Acknowledgements}

We would like to thank the Editage (http://www.editage.cn) for English language editing.

\section{Authors' contributions}

All authors have read and approved the final version of the manuscript.

\section{Funding}

This research was supported by funding from the Key Research and Development Project Key Program of Shanxi Province, China (grant no. 201703D211001).

\section{Availability of data and materials}

All data can be shared upon reasonable request. The data in Tables 1 and 2 can be referenced. Full genome sequence data can be obtained by email.

\section{Declarations}

\section{Ethics approval and consent to participate}

This study was conducted in accordance with the ethical guidelines of Shanxi Agricultural University (SAU; Taigu, China). Prior to the commencement of the study, ethical approval was granted by the Institutional Animal Care and Use Committee, Shanxi Agricultural University.

\section{Consent for publication}

Not applicable.

\section{Competing interests}

The authors declare no conflicts of interest.

Received: 7 April 2021 Accepted: 14 May 2021

Published online: 24 June 2021

\section{References}

Allan, G., S. Krakowka, J. Ellis, and C. Charreyre. 2012. Discovery and evolving history of two genetically related but phenotypically different viruses, porcine circoviruses 1 and 2. Virus Research 164 (1/2): 4-9. https://doi.org/10.1 016/j.virusres.2011.09.013.

Beltran-Alcrudo, D., J.R. Falco, E. Raizman, and K. Dietze. 2019. Transboundary spread of pig diseases: the role of international trade and travel. BMC Veterinary Research 15 (1): 64. https://doi.org/10.1186/s12917-019-1800-5.

Bexton, S., L.C. Wiersma, S. Getu, P.R. van Run, G.M.G.M. Verjans, D. Schipper, C.M. E. Schapendonk, R. Bodewes, L. Oldroyd, B.L. Haagmans, et al. 2015. Detection of Circovirus in foxes with meningoencephalitis, United Kingdom, 2009-2013. Emerging Infectious Diseases 21 (7): 1205-1208. https://doi.org/1 0.3201/eid2107.150228.

Chen, Y., J.C. Sun, X. Tong, J. Xu, H.J. Deng, Z.G. Jiang, C.F. Jiang, J.L. Duan, J.C. Li, P. Zhou, et al. 2014. First analysis of synonymous Codon usage in porcine Circovirus. Archives of Virology 159 (8): 2145-2151. https://doi.org/10.1007/ s00705-014-2015-5.

Faccini, S., I. Barbieri, A. Gilioli, G. Sala, L.R. Gibelli, A. Moreno, C. Sacchi, C. Rosignoli, G. Franzini, and A. Nigrelli. 2017. Detection and genetic characterization of Porcine Circovirus type 3 in Italy. Transboundary and Emerging Diseases 64 (6): 1661-1664. https://doi.org/10.1111/tbed.12714.

Franzo, G., M. Legnardi, C.K. Hjulsager, F. Klaumann, L.E. Larsen, J. Segales, and M. Drigo. 2018. Full-genome sequencing of porcine Circovirus 3 field strains from Denmark, Italy and Spain demonstrates a high within-Europe genetic heterogeneity. Transboundary and Emerging Diseases 65 (3): 602-606. https:// doi.org/10.1111/tbed.12836.

Fu, X., B. Fang, J. Ma, Y. Liu, D. Bu, P. Zhou, H. Wang, K. Jia, and G. Zhang. 2018. Insights into the epidemic characteristics and evolutionary history of the porcine Circovirus type 3 in Southern China. Transboundary and Emerging Diseases 65 (2): e296-e303. https://doi.org/10.1111/tbed.12752.

Geng, S.C., H. Luo, Y.J. Liu, C. Chen, W.C. Xu, Y.L. Chen, X.L. Li, and W.H. Fang. 2019. Prevalence of porcine Circovirus type 3 in pigs in the southeastern Chinese Province of Zhejiang. BMC Veterinary Research 15 (1): 244. https://doi. org/10.1186/s12917-019-1977-7. 
Gillespie, J., T. Opriessnig, X.J. Meng, K. Pelzer, and V. Buechner-Maxwell. 2009. Porcine Circovirus type 2 and porcine Circovirus-associated disease. Journal of Veterinary Internal Medicine 23 (6): 1151-1163. https://doi.org/10.1111/j.1939-1 676.2009.0389.x.

Hamel, A.L., L.L. Lin, and G.P. Nayar. 1998. Nucleotide sequence of porcine Circovirus associated with postweaning multisystemic wasting syndrome in pigs. Journal of Virology 72 (6): 5262-5267. https://doi.org/10.1128/jvi.72.6.52 62-5267.1998.

Klaumann, F., G. Franzo, M. Sohrmann, F. Correa-Fiz, M. Drigo, J.ı. Núñez, M. Sibila, and J. Segalés. 2018. Retrospective detection of Porcine Circovirus 3 (PCV3) in pig serum samples from Spain. Transboundary and Emerging Diseases 65 (5): 1290-1296. https://doi.org/10.1111/tbed.12876.

Ku, X., F. Chen, P. Li, Y. Wang, X. Yu, S. Fan, P. Qian, M. Wu, and Q. He. 2017. Identification and genetic characterization of porcine Circovirus type 3 in China. Transboundary and Emerging Diseases 64 (3): 703-708. https://doi.org/1 $0.1111 /$ tbed.12638.

Kwon, T., S.J. Yoo, C.K. Park, and Y.S. Lyoo. 2017. Prevalence of porcine Circovirus 3 in Korean pig populations. Veterinary Microbiology 207: 178-180. https://doi. org/10.1016/j.vetmic.2017.06.013

Liu, Y.Y., S. Zhang, X.H. Song, B. Hou, X.X. Gu, B.L. Zhao, L. Yang, C.B. Wang, and Z. Zhou. 2019. The prevalence of porcine Circovirus type 3 isolates in pig farms in China. Transboundary and Emerging Diseases 66 (5): 2143-2151. https://doi. org/10.1111/tbed.13266.

Nawagitgul, P., I. Morozov, T. Sirinarumitr, S.D. Sorden, and P.S. Paul. 2000. Development of probes to differentiate porcine Circovirus types 1 and 2 in vitro by in situ hybridization. Veterinary Microbiology 75 (1): 83-89. https:// doi.org/10.1016/S0378-1135(00)00199-1.

Opriessnig, T., and I. Langohr. 2013. Current state of knowledge on porcine Circovirus type 2-associated lesions. Veterinary Pathology 50 (1): 23-38. https:// doi.org/10.1177/0300985812450726.

Palinski, R., P. Piñeyro, P.C. Shang, F.F. Yuan, R. Guo, Y. Fang, E. Byers, and B.M. Hause. 2017. A porcine Circovirus distantly related to known circoviruses is associated with porcine dermatitis and nephropathy syndrome and reproductive failure. Journal of Virology 91 (1): e01879-e01816. https://doi. org/10.1128/jvi.01879-16.

Phan, T.G., F. Giannitti, S. Rossow, D. Marthaler, T.P. Knutson, L. Li, X. Deng, T. Resende, F. Vannucci, and E. Delwart. 2016. Detection of a Circovirus PCV 3 in pigs with cardiac and multi-systemic inflammation. Virology Journal 13 (1): 184. https://doi.org/10.1186/s12985-016-0642-z.

Qi, S., M. Su, D. Guo, C. Li, S. Wei, L. Feng, and D. Sun. 2019. Molecular detection and phylogenetic analysis of porcine Circovirus type 3 in 21 Provinces of China during 2015-2017. Transboundary and Emerging Diseases 66 (2): 1004 1015. https://doi.org/10.1111/tbed.13125.

Rosario, K., M. Breitbart, B. Harrach, J. Segalés, E. Delwart, P. Biagini, and A. Varsani. 2017. Revisiting the taxonomy of the family Circoviridae: establishment of the genus Cyclovirus and removal of the genus Gyrovirus. Archives of Virology 162 (5): 1447-1463. https://doi.org/10.1007/s00705-017-3247-y.

Segalés, J. 2012. Porcine Circovirus type $2\left(\mathrm{PCV}_{2}\right)$ infections: Clinical signs, pathology and laboratory diagnosis. Virus Research 164 (1/2): 10-19. https:// doi.org/10.1016/j.virusres.2011.10.007.

Shen, H., X. Liu, P. Zhang, L. Wang, Y. Liu, L. Zhang, P. Liang, and C. Song. 2018. Genome characterization of a porcine Circovirus type 3 in South China. Transboundary and Emerging Diseases 65 (1): 264-266. https://doi.org/1 $0.1111 /$ tbed.12639.

Stadejek, T., A. Woźniak, D. Miłek, and K. Biernacka. 2017. First detection of porcine Circovirus type 3 on commercial pig farms in Poland. Transboundary and Emerging Diseases 64 (5): 1350-1353. https://doi.org/10.1111/tbed.12672.

Sukmak, M., N. Thanantong, P. Poolperm, A. Boonsoongnern, N. Ratanavanichrojn, P. Jirawattanapong, Y. Woonwong, N. Soda, T. Kaminsonsakul, S. Phuttapatimok, et al. 2019. The retrospective identification and molecular epidemiology of porcine Circovirus type $3\left(\mathrm{PCV}_{3}\right)$ in swine in Thailand from 2006 to 2017. Transboundary and Emerging Diseases 66 (1): 611-616. https:// doi.org/10.1111/tbed.13057.

Tarián, Z.L., J.J. Pénzes, R.P. Tóth, and M. Benkő. 2014. First detection of Circoviruslike sequences in amphibians and putative circoviruses in fishes. Acta Veterinaria Hungarica 62 (1): 134-144. https://doi.org/10.1556/AVet.2013.061.

Todd, D., M.S. McNulty, B.M. Adair, and G.M. Allan. 2001. Animal circoviruses. Advances in Virus Research 57: 1-70. https://doi.org/10.1016/s0065-3527(01 )57000-1.

Tomás, A., L.T. Fernandes, A. Sánchez, and J. Segalés. 2010. Time course differential gene expression in response to porcine Circovirus type 2 subclinical infection. Veterinary Research 41 (1): 12. https://doi.org/10.1051/ vetres/2009060.

Wen, S., W. Sun, Z. Li, X. Zhuang, G. Zhao, C. Xie, M. Zheng, J. Jing, P. Xiao, M. Wang, et al. 2018. The detection of porcine Circovirus 3 in Guangxi, China. Transboundary and Emerging Diseases 65 (1): 27-31. https://doi.org/10.1111/ tbed.12754.

Xu, P.L., Y. Zhang, Y. Zhao, H.H. Zheng, H.Y. Han, H.X. Zhang, H.Y. Chen, M.F. Yang, and L.L. Zheng. 2018. Detection and phylogenetic analysis of porcine Circovirus type 3 in central China. Transboundary and Emerging Diseases 65 (5): 1163-1169. https://doi.org/10.1111/tbed.12920.

Ye, X.Y., M. Berg, C. Fossum, P. Wallgren, and A.L. Blomström. 2018. Detection and genetic characterisation of porcine Circovirus 3 from pigs in Sweden. Virus Genes 54 (3): 466-469. https://doi.org/10.1007/s11262-018-1553-4.

Yuzhakov, A.G., S.A. Raev, K.P. Alekseev, T.V. Grebennikova, O.A. Verkhovsky, A.D. Zaberezhny, and T.I. Aliper. 2018. First detection and full genome sequence of porcine Circovirus type 3 in Russia. Virus Genes 54 (4): 608-611. https://doi. org/10.1007/s11262-018-1582-Z.

Zheng, S., X. Wu, L. Zhang, C. Xin, Y. Liu, J. Shi, Z. Peng, S. Xu, F. Fu, J. Yu, et al. 2017. The occurrence of porcine Circovirus 3 without clinical infection signs in Shandong Province. Transboundary and Emerging Diseases 64 (5): 13371341. https://doi.org/10.1111/tbed.12667.

Zhou, J.Y., Chen, Q.X., Ye, J. X., Shen, H.G., Chen, T.F., Shang, S.B. 2018. Serological investigation and genomic characterization of PCV2 isolates from different geographic regions of Zhejiang province in China. Vet Res Commun 30 (2): 205-220. https://doi.org/10.1007/s11259-006-3203-X.

Zou, Y.W., N. Zhang, J.X. Zhang, S.J. Zhang, Y.F. Jiang, D.L. Wang, Q.H. Tan, Y. Yang, and N.D. Wang. 2018. Molecular detection and sequence analysis of porcine Circovirus type 3 in sow sera from farms with prolonged histories of reproductive problems in Hunan, China. Archives of Virology 163 (10): 2841 2847. https://doi.org/10.1007/s00705-018-3914-7.

\section{Publisher's Note}

Springer Nature remains neutral with regard to jurisdictional claims in published maps and institutional affiliations.

Ready to submit your research? Choose BMC and benefit from:

- fast, convenient online submission

- thorough peer review by experienced researchers in your field

- rapid publication on acceptance

- support for research data, including large and complex data types

- gold Open Access which fosters wider collaboration and increased citations

- maximum visibility for your research: over $100 \mathrm{M}$ website views per year

At BMC, research is always in progress.

Learn more biomedcentral.com/submissions 